\title{
The role of risk perception in explaining parental sunscreen use
}

Citation for published version (APA):

de Vries, H., van Osch, L., Eijmael, K., Smerecnik, C., \& Candel, M. (2012). The role of risk perception in explaining parental sunscreen use. Psychology \& Health, 27(11), 1342-1358.

https://doi.org/10.1080/08870446.2012.684059

Document status and date:

Published: 01/01/2012

DOI:

10.1080/08870446.2012.684059

Document Version:

Publisher's PDF, also known as Version of record

Document license:

Taverne

Please check the document version of this publication:

- A submitted manuscript is the version of the article upon submission and before peer-review. There can be important differences between the submitted version and the official published version of record.

People interested in the research are advised to contact the author for the final version of the publication, or visit the DOI to the publisher's website.

- The final author version and the galley proof are versions of the publication after peer review.

- The final published version features the final layout of the paper including the volume, issue and page numbers.

Link to publication

\footnotetext{
General rights rights.

- You may freely distribute the URL identifying the publication in the public portal. please follow below link for the End User Agreement:

www.umlib.nl/taverne-license

Take down policy

If you believe that this document breaches copyright please contact us at:

repository@maastrichtuniversity.nl

providing details and we will investigate your claim.
}

Copyright and moral rights for the publications made accessible in the public portal are retained by the authors and/or other copyright owners and it is a condition of accessing publications that users recognise and abide by the legal requirements associated with these

- Users may download and print one copy of any publication from the public portal for the purpose of private study or research.

- You may not further distribute the material or use it for any profit-making activity or commercial gain

If the publication is distributed under the terms of Article $25 \mathrm{fa}$ of the Dutch Copyright Act, indicated by the "Taverne" license above, 


\section{The role of risk perception in explaining parental sunscreen use}

Hein de Vries, Liesbeth van Osch , Kim Eijmael, Chris Smerecnik \& Math Candel

To cite this article: Hein de Vries, Liesbeth van Osch, Kim Eijmael, Chris Smerecnik \& Math Candel (2012) The role of risk perception in explaining parental sunscreen use, Psychology \& Health, 27:11, 1342-1358, DOI: 10.1080/08870446.2012.684059

To link to this article: https://doi.org/10.1080/08870446.2012.684059

曲 Published online: 14 May 2012.

Submit your article to this journal 준

LII Article views: 729

Q View related articles $₫$

4 Citing articles: 7 View citing articles ¿ 


\title{
The role of risk perception in explaining parental sunscreen use
}

\author{
Hein de Vries ${ }^{\mathrm{ab} *}$, Liesbeth van Osch ${ }^{\mathrm{ab}}$, Kim Eijmael ${ }^{\mathrm{ab}}$, \\ Chris Smerecnik $^{\mathrm{ab}}$ and Math Candel ${ }^{\mathrm{ac}}$ \\ ${ }^{a}$ Care and Public Health Research Institute, Maastricht University, Maastricht, \\ The Netherlands; ${ }^{b}$ Department of Health Promotion, Maastricht University, Maastricht, \\ The Netherlands; ${ }^{c}$ Department of Methodology and Statistics, Maastricht University, \\ Maastricht, The Netherlands
}

(Received 19 March 2012; final version received 4 April 2012)

\begin{abstract}
Objective: This study assessed: (1) whether risk perceptions about skin cancer were related to parent's use of sunscreen on their children; (2) which combination of assessments susceptibility and severity best explain parental sunscreen protection behaviours and (3) whether risk perceptions influence behaviour directly through intentions or through attitudes, subjective norms and self-efficacy.

Design: Two longitudinal studies assessed sunscreen protection behaviours of parents for their toddlers $(N=391)$ and young children $(N=436)$.

Main outcome measure: Parent's use of sunscreen on their children.

Results: Risk perceptions correlated with future sunscreen protection behaviours of parents but were lower than those of attitude, social influence and self-efficacy. Treating susceptibility and severity as an additive function resulted in the best model fit. Risk perceptions were related with future intention and future sunscreen protection behaviour, but the effects were mediated through attitude, social influence and self-efficacy.

Conclusions: Our path analyses suggest treating susceptibility and severity as an additive function. A multiplicative model without main effects although often used - had the poorest fit. Risk perceptions influence behaviour by influencing attitudinal and self-efficacy beliefs. Addressing risk perceptions in health communication programs is relevant when the purpose is to increase awareness and to influence attitudes and self-efficacy.
\end{abstract}

Keywords: risk perception; skin cancer; Health Belief Model; Protection Motivation Theory; I-Change Model

\section{Introduction}

Risk perception studies examine people's judgements concerning hazardous activities and technologies (Slovic, 1987). Risk perceptions (i.e. beliefs about potential harm) are therefore included in several health behaviour models (Schwarzer, 2008; Sutton, 1987; Weinstein \& Nicolich, 1993). Yet, some models do not address them as a specific factor but as a subset of specific health beliefs. Examples are Social Cognition Theory (Bandura, 1986), the Reasoned Action Approach (RAA) (Fishbein \& Ajzen, 2010) and the Trans Theoretical Model (TTM) (Prochaska \&

*Corresponding author. Email: hein.devries@gvo.unimaas.nl 
Velicer, 1997). Other models explicitly include risk perceptions as a separate factor. Examples of these models are the Health Belief Model (HBM) (Janz \& Becker, 1984), Protection Motivation Theory (PMT) (Rogers, 1975), the Health Action Process Approach model (HAPA) (Schwarzer, Schulz, Ziegelmann, \& Lippke, 2007) and the I-Change (de Vries, Mesters, van der Steeg, \& Honing, 2005). This raises the question whether risk perceptions should be regarded as a separate factor within health behaviour models. The first goal of this research is therefore to assess the value of risk perceptions in predicting behaviour within the context of other social cognitive constructs, such as attitudes, social influence beliefs and self-efficacy.

A problematic issue relating to risk perceptions, concerns its measurement and conceptualisation (see, e.g. Abraham \& Sheeran, 2005; Brewer et al., 2007). Studies analysing the impact of severity and susceptibility on health behaviour show effect sizes ranging from 0.08 to 0.20 , but many studies used cross-sectional designs and often found inconsistent contributions of risk perceptions on behaviour (Abraham \& Sheeran, 2005; Brewer et al., 2007). Additionally, cross-sectional relations between risk perception and behaviour (and sometimes longitudinal relations as well) can be misleading as people take into account their current health behaviour when estimating their risk (Weinstein \& Kwitel, 2007). Milne, Sheeran, and Orbell (2000) found effect sizes $(r)$ of 0.12 for susceptibility and no significant effects for severity. Abraham and Sheeran (2005) concluded that susceptibility and severity may be significant predictors but with small effects, and that many studies suffered from poor measurement and low reliability and validity. Several explanations can be given for these inconsistencies.

First, risk perceptions may not have the same impact on all health behaviours. Janz and Becker (1984) already described that perceived susceptibility was a stronger contributor to understanding preventive health behaviours than sick-role behaviours. Brewer et al. (2007) suggested that risk perceptions may be more important for specific behaviours that reduce threats (i.e. sunscreen use) and less important for behaviours, such as exercise and diet, that have a wide range of health and nonhealth consequences.

Second, no consensus exists with respect to core constructs needed to measure risk perceptions. Some studies assess severity and susceptibility (e.g. Harrison, Mullen, \& Green, 1992; Janz \& Becker 1984). Others use vulnerability (e.g. Floyd, Prentice-Dunn, \& Rogers, 2000; Milne et al., 2000), use both terms interchangeably (e.g. Brewer et al., 2007), distinguish likelihood, susceptibility and severity (e.g. Brewer et al., 2007) or use combinations (e.g. Norman \& Brain, 2007; Sniehotta, Scholz, \& Schwarzer, 2006). Different assessment methods are also used. Some use likelihood scales to assess susceptibility (e.g. Conner, Kirk, Cade, \& Barret, 2001); others use Weinstein's suggestion (1988) to (also) use comparative risk assessments (e.g. Schwarzer et al., 2007). This gives mix results in psychometric problems and in problems for comparing studies. Additionally, different analytic methods are employed to measure risk perception (Abraham \& Sheeran, 2005). Some studies use the concepts severity and susceptibility separately (see, e.g. Li et al., 1984). Others suggest an additive function assuming two (independent) main effects of susceptibility and severity (see, e.g. Craciun, Schüz, Lippke, \& Schwarzer, 2010; Lescano \& Rodrigue, 1997). In some studies a multiplicative function is used (see, e.g. Conner and Norman, 1994; Rimal \& Real, 2003), assuming that the effect of one of the constructs on behaviour or cognitions depends on the strength of the other one (e.g. feeling susceptible to some illness will only have effects if this illness is also 
considered serious). The latter method, however, is subject to statistical and empirical criticism (see, e.g. Evans, 1991; Gagné \& Godin, 2000). The second goal of our research aims at exploring the effects of different analytic methods in predicting future behaviour when severity and susceptibility are measured.

Third, risk perceptions may play a more distal role by influencing other beliefs (Norman \& Conner, 2005). Yet, the HBM hypothesises susceptibility and severity to influence behaviour directly. PMT uses the terms probability, likelihood or vulnerability to describe susceptibility. PMT conceptualises risk perceptions as the result of multiplying susceptibility with severity (Rogers, 1975). PMT suggests a direct influence of risk perception on protection motivation by the weighing of intrinsic and extrinsic rewards minus severity and probability. A further elaboration of HBM and PMT by the HAPA model uses the same conceptualisation of risk perceptions as the HBM in principle, but assumes that risk perceptions influence intentions as does PMT (Schwarzer et al., 2007). Whereas HBM and PMT suggest direct influences of risk perception on respectively behaviour and intentions, other models suggest a more distal role of risk perceptions, such as the Precaution Adoption Model (Weinstein, 1988), the HAPA model (Schwarzer et al., 2007), the Risk Perception Attitude Framework (Rimal \& Real, 2003) and the I-Change Model (de Vries, Kremers, Smeets, Brug, \& Eijmael, 2008). These models suggest that risk perceptions exert their influence by making a person aware of their risk for a particular health threat. When aware of this situation, a person may become more motivated to process information further and deeper. Furthermore, although this is not stated as explicitly by the Precaution Adoption Model and the HAPA model, the I-Change Model assumes that the effects of risk perceptions will be mediated through attitudes and self-efficacy, a finding also found in earlier cross-sectional studies (de Vries, Mesters, et al., 2005; de Vries, Mesters, van 't Riet, Willems, \& Reubsaet, 2006). Ronis and Harel (1989) also found that severity effects were mediated by the benefits factor from the HBM. By not regarding risk perceptions as a distal factor preceding cognitions such as attitudes and self-efficacy, and including them in one regression equation together with these factors, one may erroneously conclude that risk perceptions are not important and thus overlook their distal role. The third goal of this research pertains to the exploration of this issue.

This study took place within the context of skin cancer prevention and sunscreen use of parents to protect their young children. Although skin cancer mortality is relatively low, morbidity and collateral effects (e.g. high personal costs through disfigurement; health care costs) are significant (de Vries Lezwijn, Hol, \& van der steeg 2005; de Vries, van der Rhee, \& Coebergh, 2006). Skin cancer incidence is increasing rapidly and may reach epidemic proportions, thus requiring preventive actions. A recent study revealed that more than $50 \%$ of Dutch dermatologists' time is spent on skin cancer and skin premalignant neoplasms, implying an incidence of approximately 80,000 skin malignant neoplasms. This indicates at least a double in the amount of skin cancer cases compared with the expected incidence of 37,000 cases in the Netherlands (Van der Geer, Reijers, van Tuijl, de Vries, \& Krekels, 2010). Childhood UV exposure and the number of sunburns in a child are central risk factors for later skin cancer development (Whiteman, Whiteman, \& Green, 2001). Children and their parents and caregivers therefore form an important target group for preventive interventions. Parents may not always be aware of the importance of protecting their children and parental sun protection practices are often inadequate since parents are not always aware of the recommendations (Severi 


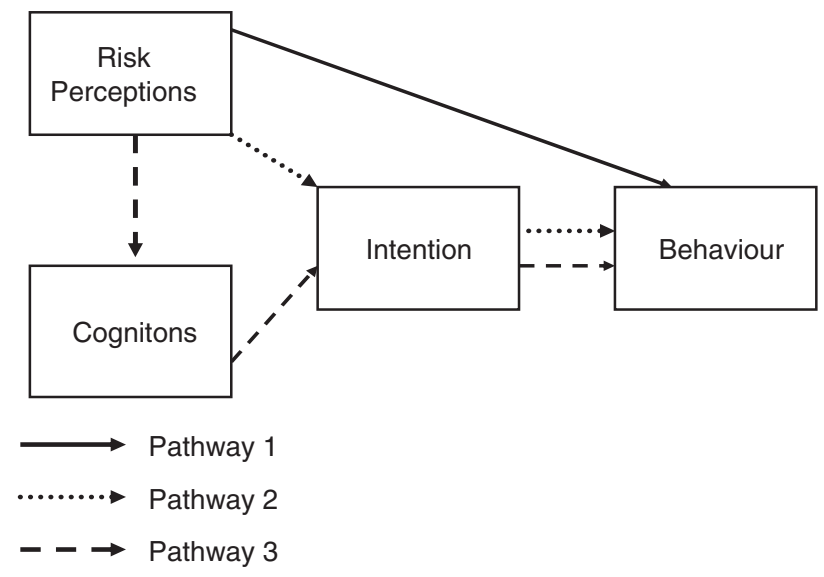

Figure 1. Potential pathways of influence of risk perception.

et al., 2002), which in the Netherlands are to apply SF20+ on their children 30 minutes before going outside when they will be outside in the sun; seeking shade in the middle of the day when the UV-radiation is strongest, and covering up the skin with protective clothing and a hat or cap (Van Osch, Reubsaet, Lechner, \& de Vries, 2008).

In sum, the goals of our research are to assess: (1) the extent to which risk perceptions about skin cancer were related to parental sunscreen behaviour within the context of other social cognitive constructs, such as attitudes, social influence beliefs and self-efficacy; (2) which combination of susceptibility and severity would best explain parental sunscreen protection behaviours in their children and (3) whether the influence of risk perceptions would be exerted directly on behaviour (as suggested by the HBM), or would be mediated by intentions (as suggested by PMT) or by cognitions (as suggested by the I-Change Model and partly by the HAPA model that also regards risk perceptions as a distal factor but posits a direct influence on intention) (Schwarzer et al., 2007). These three potential pathways of influence of risk perceptions are depicted in Figure 1.

\section{Method}

\section{Subjects and recruitment}

Data from two longitudinal studies on the sunscreen use of parents as applied to their children were used. In study 1, 391 parents of children aged 0-2 years participated. Baseline questionnaires were disseminated in April of 2005; the posttest took place five months after baseline and had an identical content. To reach parents, 116 day-care centres in the Dutch province of Limburg were approached and asked to distribute questionnaires to parents of $0-2$ year olds. A total of 59 $(50.8 \%)$ day-care centres agreed to participate. Reasons for declining to participate included not having any 0-2 year olds at the day-care centre, no time or being involved in other research. A first questionnaire, a letter explaining the study goal and a stamped return envelope were distributed in April 2005. In total, 494 
respondents indicated to be willing to fill out a baseline and post-test questionnaire after 18 weeks; $402(81.4 \%)$ respondents returned it at post-test. After missing-data analysis (respondents $>10 \%$ missing values were deleted), 391 respondents $(79.1 \%$ ) were included in study 1.

Study 2 targeted parents of children in the age of 6-9 years; the parents were all members of an Internet panel. In April 2005, 925 parents indicated to be willing to fill out a baseline measurement and a follow-up five months later, consisting of the same questions. Participants were explained that they would receive $€ 2$ after completing both questionnaires. Of the 925 parents, $495(53.5 \%)$ filled out the follow-up questionnaire. In 59 cases the two questionnaires were filled out by a different parent; these respondents were excluded, leaving 436 parents $(47.1 \%)$ for analysis. A dropout-analysis employing logistic regression, examined which covariates were associated with dropout at post-test. For study 1 we included all demographic and motivational predictors in the regression equation to understand drop-out. Only previous behaviour was related to drop-out, indicating that those who dropped out were more likely to already apply sunscreen adequately at baseline $(\mathrm{OR}=1.086 ; p=0.001)$. For study 2 we also included all demographic and motivational predictors in the regression equation to understand drop-out. Only gender was related to drop-out, indicating that more males dropped out $(\mathrm{OR}=0.638 ; p=0.005)$.

\section{Questionnaire}

The items of the questionnaires were derived from related studies on sunscreen use and pilot studies identifying salient beliefs (de Vries, Lezwijn, et al., 2005; de Vries, van der Rhee, et al., 2006; van Osch et al., 2008). Age, gender, marital status (alone or living with partner/spouse) and educational level were assessed. Parental and child skin types were assessed by asking to indicate whether they: burn very fast, hardly tan (type 1); type 2: burn fast, tan slowly (type 2); do not burn fast; easily tan (type 3 ); rarely burn, tan easily (type 4); hardly ever burn, tan easily (type 5); never burn, tan easily (type 6) (Fitzpatrick, 1975).

Risk perceptions in both studies assessed severity and susceptibility. Perceived susceptibility was assessed by asking the parents to indicate their answer to one of the five alternatives for the question: If I do not adequately protect my child from the sun, his or her risk of developing skin cancer in the future is: very low (1) to very high (5). Perceived severity was assessed by asking: If my child would develop skin cancer in the future, I would find this not serious (1) to very serious (5).

Both studies used five items to assess the attitude of parents towards using sunscreen for their children when outside in the sun (study 1 Cronbach's $\alpha=0.79$; study 2 Cronbach's $\alpha=0.75$ ). Parents were asked to indicate their answer on the following five statements: Using sunscreen SPF $20+$ is a pleasant way to protect my child from the sun $(1=$ not pleasant to $4=$ very pleasant); using sunscreen SPF $20+$ is important for my child's health ( $1=$ not important to $4=$ very important); using sunscreen SPF $20+$ is annoying during my child's playing $(1=$ very annoying to $4=$ not annoying); using sunscreen SPF $20+$ is inconvenient $(1=$ very inconvenient to $4=$ not inconvenient); using sunscreen SPF $20+$ is unnecessary $(1=$ very unnecessary to $4=$ not unnecessary). 
In both studies, three items were used to measure social influence of salient others (study 1 Cronbach's $\alpha=0.79$; study 2 Cronbach's $\alpha=0.73$ ). Social modelling was measured by asking: How often do important people in your environment use sunscreen SPF $20+$ to protect their children from the sun? $(1=$ hardly ever to $4=$ always). Social norms were assessed by asking: How important do important people in your environment find it to use sunscreen SPF $20+$ on their children to protect them from the sun? ( $1=$ definitely not important to $4=$ definitely important $)$. Social support was measured by asking: How often do important people in your environment support you to use sunscreen SPF $20+$ on your child to protect it from the sun? ( 1 = hardly ever to $4=$ always $)$.

Self-efficacy to apply sunscreen use on their child was assessed by four items on a seven-point scale $(-3=$ definitely not, $+3=$ yes, definitely) in study $1(\alpha=0.76)$ (e.g. I feel able to use sunscreen to protect my child from the sun on a half-cloudy day). In study 2, self-efficacy was measured by one item ('Do you think you will be able to adequately use sunscreen SPF $20+$ on your child to protect him/her from the sun?' $1=$ definitely not, $7=$ definitely yes).

Parents' intention to use sunscreen to protect their child was measured by three items on a seven-point scale $(-3=$ definitely not, $+3=$ yes, definitely $)$ in study 1 (Cronbach's $\alpha=0.74)$. Parents were asked to indicate if they were intending to apply sunscreen SPF $20+$ on a sunny day, 30 minutes before going outside and every two hours. Using these three items, a mean score for intention to apply sunscreen SPF $20+$ was computed). In study 2 , intention was measured by one item ('Do you intend to adequately use sunscreen SPF20+ on your child to protect him/her from the sun?' $1=$ definitely no, $7=$ definitely yes).

Parents indicated in both studies to what extent they protected their child when playing outside in the sun by applying sunscreen SPF $20+(0=$ never; $1=$ rarely; $2=$ sometimes; $3=$ often; $4=$ always).

\section{Analysis}

First, correlations assessed the relationship of baseline risk perceptions with post-test cognitions and behaviour, using the different ways of assessing risk perceptions: as separate constructs, as an additive (severity + susceptibility) function or as a multiplicative (severity * susceptibility) function. Second, we tested which of the following models best described sunscreen use through path analysis (in MPLUS) using Full Information Maximum Likelihood estimation (Muthén \& Muthén, 2006). Model 1 employed the separate constructs of severity and susceptibility as predictors of sunscreen use (Model $1=\beta_{0}+\beta_{1} X_{1}+\beta_{2} X_{2}$ ); model 2 implemented the additive function Severity + Susceptibility (Model $2=\beta_{0}+\beta_{1}\left(X_{1}+X_{2}\right)$. Model 3 used the multiplicative function as often used by the HBM, Severity $\times$ Susceptibility (Model $3=\beta_{0}+\beta_{1}\left(X_{1} \times X_{2}\right)$. Model 4 used a model with main and interaction effects: Severity, Susceptibility and Severity $\times$ Susceptibility (Model $4=\beta_{0}+\beta_{1} X_{1}+$ $\beta_{2} X_{2}+\beta_{3}\left(X_{1} \times X_{2}\right)$. In order to be able to compare these models, they should be nested. In model 1 and 2 , a Severity $\times$ Susceptibility interaction term was therefore added to the model but its regression coefficient was constrained to zero. In model 2 , the pathways from susceptibility and severity to the motivational factors (attitude, social influence and self-efficacy) were set equal; in model 3, they were constrained to zero. Models 1, 2 and 4 are nested models, and were compared statistically through 
Table 1. General characteristics of the sample.

\begin{tabular}{lcc}
\hline & Study 1 & Study 2 \\
\hline Gender & & \\
Male & $N=28 ; 7.2 \%$ & $N=100 ; 22.9 \%$ \\
Female & $N=362 ; 92.8 \%$ & $N=336 ; 77.1 \%$ \\
Age & $33.2(\mathrm{SD}=3.7)$ & $36.4(\mathrm{SD}=5.2)$ \\
Education & $N=12 ; 3.1 \%$ & $N=153 ; 35.1 \%$ \\
Low & $N=148 ; 38.1 \%$ & $N=205 ; 47.0 \%$ \\
Medium & $N=228 ; 58.8 \%$ & $N=78 ; 17.9 \%$ \\
High & months $(\mathrm{SD}=5.9)$ & 7.3 years $(\mathrm{SD}=1.1)$ \\
Age of child & $N=382 ; 97.7 \%$ & $N=69 ; 84.2 \%$ \\
Family situation & $N=9 ; 2.3 \%$ & $N=367 ; 16 \%$ \\
Living alone & & \\
With partner & $N=31 ; 8.8 \%$ & $N=30 ; 6.9 \%$ \\
Skin type child & $N=167 ; 47.3 \%$ & $N=243 ; 55.7 \%$ \\
Type 1 & $N=138 ; 39.1 \%$ & $N=55 ; 12.6 \%$ \\
Type 2 & $N=11 ; 3.1 \%$ & $N=13 ; 3.0 \%$ \\
Type 3 & $N=5 ; 1.4 \%$ & $N=5 ; 1.1 \%$ \\
Type 4 & $N=1 ; 0.3 \%$ & \\
Type 5 & $N=11 ; 2.8 \%$ & $N=84 ; 19.3 \%$ \\
Type 6 & $N=38 ; 9.8 \%$ & $N=78 ; 17.9 \%$ \\
Applying sunscreen when child is outside & $N=95 ; 21.8 \%$ \\
Never & $N=47 ; 12.1 \%$ & $N=48 ; 11.0 \%$ \\
Sometimes & $N=151 ; 38.9 \%$ & \\
Often & $N=141 ; 36.3 \%$ & \\
Most of the times & & \\
Always & & \\
\hline
\end{tabular}

successive likelihoods ratio tests, starting with the most complex model (model 4). Analyses were repeated by correcting for baseline sunscreen behaviour to assess potential differences in model outcomes.

Overall model fit was assessed using the Comparative Fit Index (CFI), the Tucker-Lewis-Index (TLI) (>0.90, preferably >0.95) and the Root-Mean-Square Error of Approximation (RMSEA <0.08; preferably <0.06) (Hu \& Bentler, 1999).

\section{Results}

\section{Characteristics of the samples}

Table 1 provides an overview of the characteristics of the participants. In both studies, the majority of the participants were female and lived together with a partner or spouse. Study 1 participants were mostly highly educated, which can be explained by the fact that they were recruited from day-care centres.

\section{The role of risk perception and other cognitions in understanding future parental sunscreen behaviour}

Table 2 shows significant correlations of all T1 constructs with T2 behaviour for Study 1 (with severity only being borderline significant; $p<0.06$ ). The risk perception constructs had low correlations with T2 behaviour (all <0.15). 


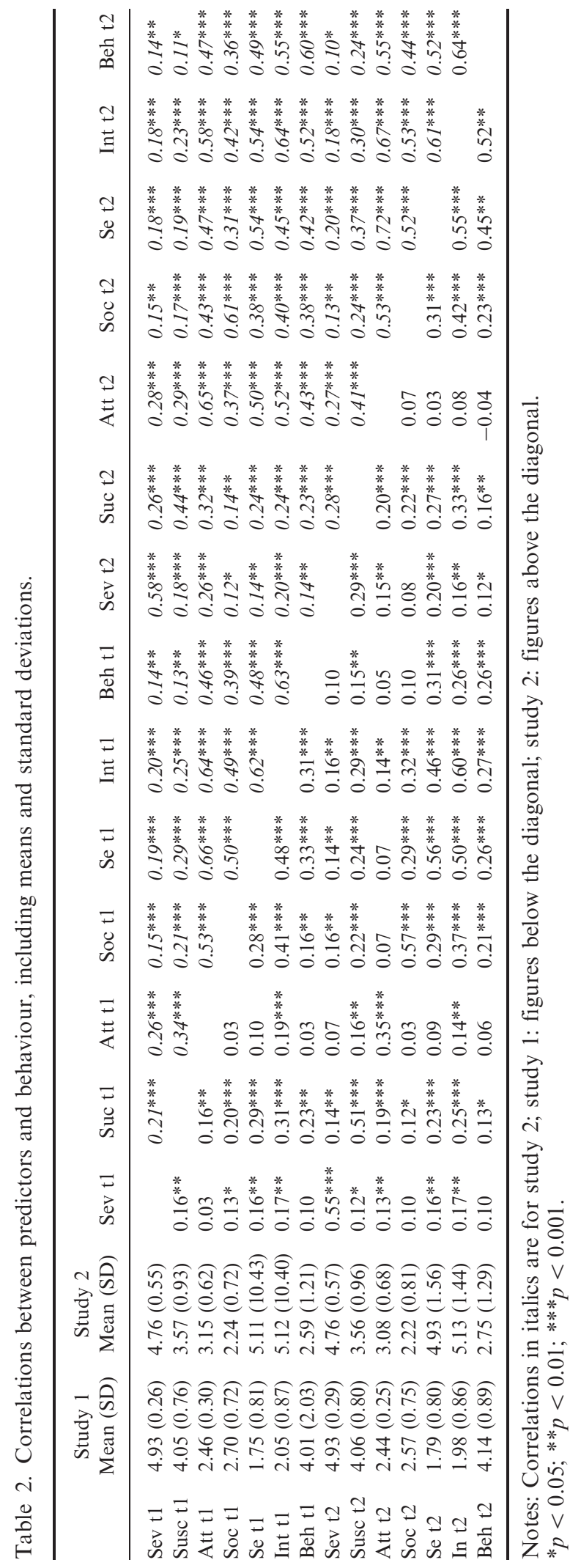


Table 3. Correlations of the baseline risk perception constructs with follow-up cognitions and sunscreen behaviour of parents of study 1 and study 2 .

\begin{tabular}{|c|c|c|c|c|}
\hline & $\begin{array}{l}\text { Severity } \\
\text { (T1) }\end{array}$ & $\begin{array}{l}\text { Susceptibility } \\
\text { (T1) }\end{array}$ & $\begin{array}{l}\text { Additive } \\
\text { (T1) }\end{array}$ & $\begin{array}{l}\text { Multiplicative } \\
\text { (T1) }\end{array}$ \\
\hline \multicolumn{5}{|l|}{ Study 1} \\
\hline Attitude (T2) & $0.13 * *$ & $0.19 * *$ & $0.32 * *$ & 0.31 \\
\hline Social influence (T2) & 0.10 & $0.12 *$ & $0.14 * *$ & $0.14 * *$ \\
\hline Self-efficacy (T2) & $0.16^{* *}$ & $0.23 * * *$ & $0.26^{* *}$ & $0.25^{* *}$ \\
\hline Intention (T2) & $0.17 * *$ & $0.25 * * *$ & $0.28 * *$ & $0.27 * *$ \\
\hline Behaviour (T2) & 0.10 & $0.13^{*}$ & $0.15^{* *}$ & $0.14 * *$ \\
\hline \multicolumn{5}{|l|}{ Study 2} \\
\hline Attitude (T2) & $0.28 * * *$ & $0.29 * * *$ & $0.40 * *$ & 0.35 \\
\hline Social influence (T2) & $0.15^{* *}$ & $0.17 * * *$ & $0.21 * * *$ & $0.20 * * *$ \\
\hline Self-efficacy (T2) & $0.18 * * *$ & $0.19 * * *$ & $0.24 * * *$ & $0.22 * * *$ \\
\hline Intention (T2) & $0.18 * * *$ & $0.23 * * *$ & $0.27 * * *$ & $0.26^{* * *}$ \\
\hline Behaviour (T2) & $0.14 * *$ & $0.11 *$ & $0.15^{* *}$ & $0.14 * *$ \\
\hline
\end{tabular}

Notes: $* p<0.05, * * p<0.01, * * * p<0.001$.

The correlations of the attitude, social influences and self-efficacy with T2 behaviour were $0.21,0.12$ and 0.22 . A similar pattern for Study 2 emerged with significant correlations of all constructs with T2 behaviour. Again, the risk perception constructs had the lowest correlation with T2 behaviour (all $<0.15$ ) whereas the correlations of attitude, social influences and self-efficacy with $\mathrm{T} 2$ behaviour were $0.47,0.36$ and 0.49 .

We additionally explored whether a similar pattern emerged when correcting for the fact that in Study 1 attitude, social influence, self-efficacy and intention, and in Study 2 attitude and social influence were measured with multiple items, whereas severity and susceptibility were measured with only one item. In comparing the correlations, one should consider attenuation effects due to differences in measurement reliability. Assuming the items are parallel, the correlations for the motivational constructs were recalculated in case they would have been measured with one item. These correlations were $>0.19$ in study 1 and $>0.30$ in study 2 , showing that, even after correcting for differences in attenuation, these still exceed the correlations of the severity and susceptibility measurements. Furthermore, we found that the correlations of the additive and multiplicative functions with behaviour were not higher than those obtained when using the separate constructs. A $t$-test testing the difference between these two correlations (Ferguson, 1976) was non-significant (all $p>0.05)$.

Table 3 shows that the additive function of susceptibility and severity as assessed at baseline was most highly correlated with attitudes, social norms, self-efficacy, intention and behaviour at post-test in both studies. The highest correlations of risk perception were found with the attitude scale with correlations of $r=0.32$ in study 1 and $r=0.40$ in study 2 .

\section{How to best measure risk perception?}

To examine how susceptibility and severity influence sunscreen use, different path analysis models were compared (Table 4). The values for the fit measures CFI, TLI 
Table 4. Results of the path analyses for studies 1 and $2 .^{\text {a }}$

\begin{tabular}{|c|c|c|c|c|c|c|}
\hline & CFI & TLI & RMSEA & $\begin{array}{c}\text { Log } \\
\text { likelihood }\end{array}$ & $\begin{array}{l}R^{2} \\
(\%)\end{array}$ & Parameters \\
\hline \multicolumn{7}{|l|}{ Study 1} \\
\hline \multicolumn{7}{|l|}{ Model 1} \\
\hline Severity & 0.999 & 0.997 & 0.012 & -3802.122 & 26.7 & 28 \\
\hline Susceptibility & 0.999 & 0.994 & 0.018 & -4671.915 & 29.2 & 33 \\
\hline \multicolumn{7}{|l|}{ Model 2} \\
\hline Severity + & 1.000 & 1.008 & 0.000 & -3803.365 & 26.7 & 23 \\
\hline Susceptibility & 0.991 & 0.978 & 0.035 & -4676.841 & 29.2 & $28^{*}$ \\
\hline \multicolumn{7}{|l|}{ Model 3} \\
\hline Severity $x$ & 0.931 & 0.856 & 0.092 & -3823.878 & 27.0 & 23 \\
\hline Susceptibility (no main effects) & 0.925 & 0.812 & 0.065 & -46985.572 & 29.6 & 28 \\
\hline \multicolumn{7}{|l|}{ Model 4} \\
\hline Severity $x$ & 1.000 & 1.042 & 0.000 & -3798.478 & 27.2 & 33 \\
\hline $\begin{array}{l}\text { Susceptibility } \\
\quad \text { (with main effects) }\end{array}$ & 1.000 & 1.042 & 0.000 & -4668.069 & 29.9 & 38 \\
\hline \multicolumn{7}{|l|}{ Study 2} \\
\hline \multicolumn{7}{|l|}{ Model 1} \\
\hline Severity; & 0.994 & 0.977 & 0.049 & -4209.024 & 44.2 & 28 \\
\hline Susceptibility & 0.999 & 0.995 & 0.023 & -4715.351 & 52.4 & 33 \\
\hline \multicolumn{7}{|l|}{ Model 2} \\
\hline Severity + & 0.995 & 0.990 & 0.032 & -4210.574 & 44.0 & 23 \\
\hline Susceptibility & 1.000 & 1.001 & 0.000 & -4716.893 & 52.2 & 28 \\
\hline \multicolumn{7}{|l|}{ Model 3} \\
\hline Severity $x$ & 0.945 & 0.884 & 0.110 & -4239.297 & 44.4 & 23 \\
\hline Susceptibility (no main effects) & 0.963 & 0.908 & 0.097 & -4741.530 & 47.7 & 28 \\
\hline \multicolumn{7}{|c|}{ Model 4} \\
\hline Severity $x$ & 0.993 & 0.914 & 0.095 & -4206.814 & 44.6 & 33 \\
\hline $\begin{array}{l}\text { Susceptibility } \\
\quad \text { (with main effects) }\end{array}$ & 0.997 & 0.957 & 0.066 & -4713.952 & 52.6 & 38 \\
\hline
\end{tabular}

Notes: ${ }^{a}$ The figures in italics represent the fit statistics and number of parameters after correcting for previous behaviour.

and RMSEA suggest satisfactory outcomes for all models. Statistical comparisons of nested models were run using likelihood ratio tests, by considering the differences in $-2 \log$ likelihood of the models ( $\Delta-2$ LL). For both studies model 4 , the most complex model did not significantly improve model 1 (with separate severity and susceptibility constructs) $(\Delta-2 \mathrm{LL}=7.288, p>0.10$ for study $1 ; \Delta-2 \mathrm{LL}=4.42$, $p>0.10$ for study 2 ). Hence, model 4 can be regarded as the least parsimonious model.

Next, we tested a model in which the weights for severity and susceptibility can be regarded as different (model 1) against a model in which the importance of these two independent factors is equal (model 2). Model 1 in turn did not significantly improve model 2 (the additive model) $(\Delta-2 \mathrm{LL}=2.486, p>0.10$, for study $1 ; \Delta-2 \mathrm{LL}=3.1$, $p>0.10$, for study 2 ). The other more complex models thus did not significantly improve the additive model. Finally, since models 2 and 3 have the same number of parameters, the model with the largest log likelihood can be considered the best fitting model. Hence, the results suggest model 2 (the additive model) as the preferred solution. 
Furthermore, we reanalysed the models, now also correcting for baseline sunscreen behaviour. As can be noted from Table 3, the results are comparable to the ones described above. For both studies model 4, the most complex model, did not significantly improve model 1 (with separate severity and susceptibility constructs) ( $\Delta$ $-2 \mathrm{LL}=7.692, p>0.15$ for study $1 ; \Delta-2 \mathrm{LL}=2.798, p>0.70$ for study 2 ) or model 2 (with the additive function of severity and susceptibility) ( $\Delta-2 \mathrm{LL}=17.54$, $p>0.05$ for study $1 ; \Delta-2 \mathrm{LL}=5.882, p>0.80$ for study 2 ). Model 1 in turn did not significantly improve model 2 (the additive model) $(\Delta-2 \mathrm{LL}=9.852, p>0.05$, for study $1 ; \Delta-2 \mathrm{LL}=3.084, p>0.65$, for study 2 ). Since models 2 and 3 have the same number of parameters, the model with the largest log likelihood can be considered the best fitting model. Hence, also after correction for baseline sunscreen behaviour, model 2 (the additive model) can be considered the best model.

\section{Mediation of risk perception beliefs}

First, we assessed whether risk perception at T1 (using the additive model of risk perception) has a direct effect on intention and behaviour at T2. When correcting for previous behaviour, we found a direct significant effect of risk perception on intention for study $1(\beta=0.14 ; p<001)$. The direct effect on behaviour at T2 was borderline significant $(\beta=0.06, p=0.07)$. For study 2 the direct effect of risk perceptions on intention (also correcting for baseline behaviour) turned out to be significant $(\beta=0.12 ; p<0.001)$. A non-significant effect of risk perception on behaviour at T2 was found, probably due to the effect being small $(\beta=0.04$; $p=0.11)$.

We tested whether the indirect influence of risk perception (using the additive function) via the motivational variables and intention was significant. We used the Sobel test to assess whether the mediator variables significantly carried the influence of risk perceptions to the dependent variable (the behaviour), and thus whether the indirect effect of risk perception on T2 behaviour through the mediator variables was significant. First, we assessed mediation by intention by adding paths from risk perception to intention and from intention to behaviour. For Study 1 the indirect effect of risk perception on behaviour via intention turned out to be significant (Sobel's $Z=4.18, p<0.001$ ). This also was the case for study 2 (Sobel's $Z=4.25$, $p<0.001)$. Next, we assessed mediation by the motivational variables attitude, social influence and self-efficacy by adding paths from risk perception to each of the motivational variables and from each of the motivational variables to intention. For study 1 , there were significant indirect effects of risk perception on intention via attitude (Sobel's $Z=3.42, p<0.001$ ), via self-efficacy (Sobel's $Z=3.33, p<0.001$ ) but not via social influence (Sobel's $Z=0.83, p=0.41$ ). Similar results were obtained for study 2; there were significant indirect effects of risk perception on intention via attitude (Sobel's $Z=5.46, p<0.001$ ), via social influence (Sobel's $Z=2.33$, $p<0.05$ ) and also via self-efficacy (Sobel's $Z=2.48, p<0.05$ ). Note that in the final model, as shown in Figure 2, there were neither direct effects of risk perception on intention $(\beta=0.05, p>0.05$ for study $1 ; \beta=0.01, p>0.63$ for study 2$)$ nor on sunscreen use anymore $(\beta=-0.02, p>0.50$ for study $1 ; \beta=-0.04, p>0.63$ for study 2 ), implying that the effect of risk perception on sunscreen use is fully mediated by the motivational variables and intention. 


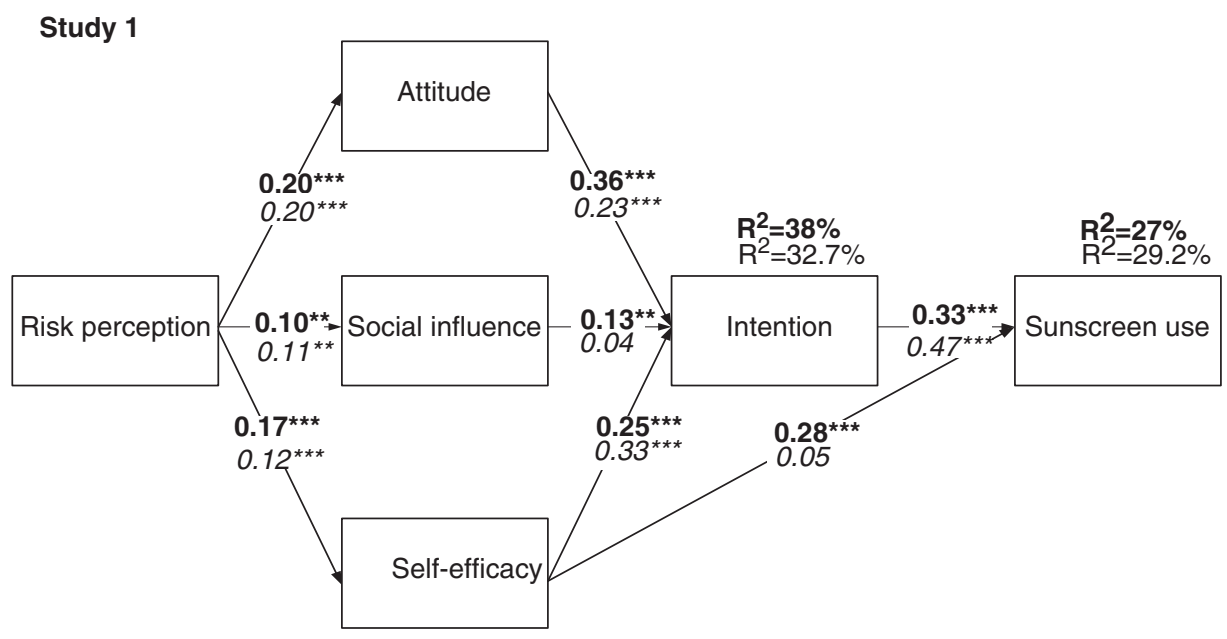

Study 2

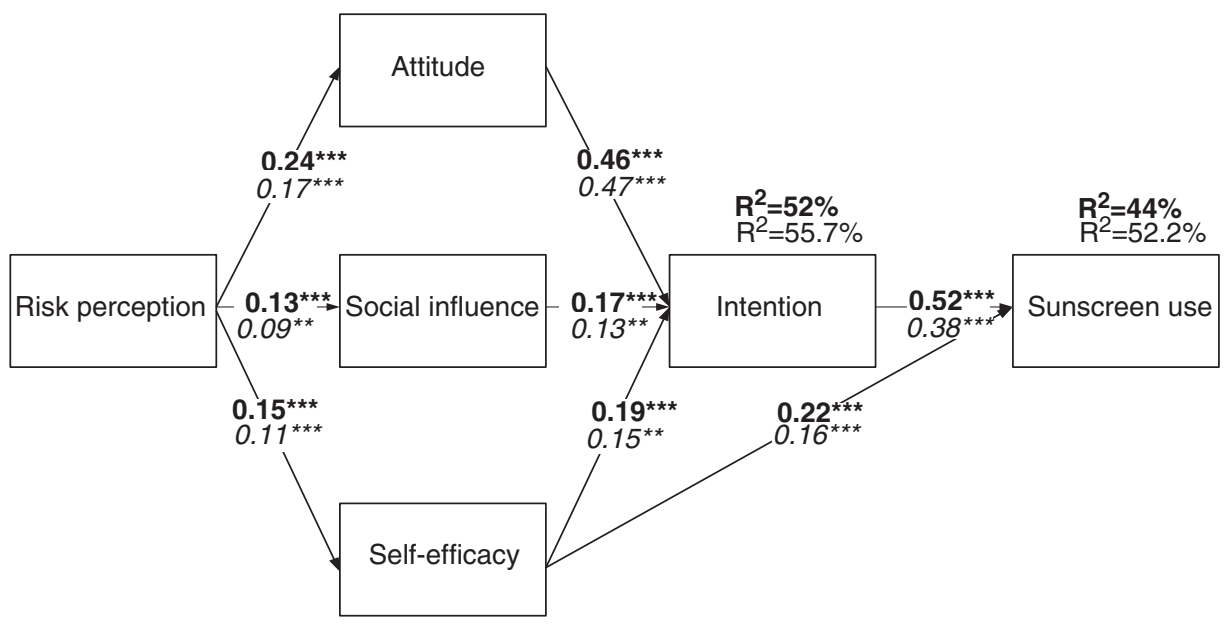

Figure 2. Path analysis model with standardised regression coefficients representing associations between risk perception, motivational variables and sunscreen use.

Notes: $* p<0.05 ; * * p<0.01 ; * * * p<0.001$. The correlations when correcting for baseline behaviour are depicted in italics.

\section{Discussion}

Two parental sunscreen use studies assessed the impact of risk perceptions on this behaviour, the most appropriate way to measure risk perception, and whether risk perception influences were mediated by attitude, social influence and self-efficacy beliefs. Both studies revealed the same main findings, despite some sample differences such as educational level and sunscreen behaviour.

First, the correlation between risk perceptions and future parental sunscreen behaviour was significant, but was mostly lower than those of attitude, social influence and self-efficacy. In line with other studies, our results indicate a modest contribution of risk perceptions within the context of other factors (Cameron, 2007; Jones, Abraham, Harris, Schulz, \& Chrispin, 2001). Second, our path analysis results 
are congruent to those reported earlier (Maddux \& Rogers, 1983; Ronis \& Harel, 1989) and revealed the best model fit for the additive function. Interestingly, the multiplicative model without main effects - very often used in health behaviour research - did not significantly improve the simpler additive model. The usage of a multiplicative model without main effects, although often used, is also not recommended because of statistical reasons (Evans, 1991; Gagné \& Godin, 2000). The support for the additive function implies that perceptions of severity and susceptibility of parents concerning the skin cancer risk of their child should be considered as two independent factors; they do not seem to influence each other, as assumed by a multiplicative function. The fact that the factors are different is also illustrated by the low correlations between the two constructs. Third, T1 risk perceptions were related with $\mathrm{T} 2$ intention and $\mathrm{T} 2$ behaviour, but the effects were mediated through attitude, social influence and self-efficacy. Hence, our two studies provide support for pattern 3, as indicated in Figure 1. Other studies also found that risk perceptions were mediated by attitudes (e.g. de Vries, Lezwijn, et al., 2005; de Vries, van der Rhee, et al., 2006; Ronis \& Harel, 1989; Ulleberg \& Rundmo, 2003) or by self-efficacy (Turner \& Mermelstein, 2005). Fourth, our findings suggest that riskperceptions are related to self-efficacy. This pattern is not often described, since most studies focus on the risk-perception-behaviour relationship or risk-perceptionattitude relationship. However, a few other studies also found a correlation between self-efficacy and risk perceptions (see, e.g. Lippke Ziegelmann, \& Schwarzer, 2004; Schwarzer et al., 2007). One explanation may be that when people feel more at risk, they may start to invest more effort in looking at the problem and identifying efforts to cope with this problem. A reversed pattern may also exist, as Bandura (1997) suggested that people with low levels of self-efficacy tend to avoid high-risk related situations. Additionally, self-efficacy can also be a moderator for risk perceptions (Ruiter, Verplanken, Kok, \& Werrij, 2003). Future research is needed to further disentangle this phenomenon.

What are the implications of our findings for intervention development? Our findings suggest that risk perceptions can be regarded as antecedents of motivational factors. Hence, risk perceptions can impact behaviour via attitudinal and selfefficacy beliefs. This finding still suggests the need for addressing risk perceptions in health communication programs in order to increase awareness and to develop positive attitudes and self-efficacy towards sunscreen use of parents for their children. The findings also suggest that addressing risk perceptions may be less relevant for people who are already convinced of the need to change their behaviour. This finding is in line with the motivational phases outlined by the I-Change Model. Yet, more research is needed to replicate our findings for other behaviours and other populations in order to be able to draw more final conclusions.

Our research is subject to limitations. First, parental self-reports may have led to over reporting of sunscreen application for their children. However, other studies showed congruence between self-reported sunscreen use and objectively assessed outcomes (e.g. sunscreen swabbing; O'Riordan et al., 2006). Second, the utilisation of susceptibility and severity is only one strategy to conceptualise risk perceptions. Weinstein (1988) suggest assessing relative risks. Third, severity and susceptibility were only measured for one type of outcome, skin cancer, possibly leading to ceiling effects since most people will agree that it is very severe. This is supported by the high mean and small standard deviations of the severity measurements found in both studies $(M=4.93, \mathrm{SD}=0.26$ for study 1 at $\mathrm{T} 1 ; M=4.76$ and $\mathrm{SD}=0.55$ for study 2 at 
T1, on a scale from 1 to 5). The resulting variance restriction will lead to weakened correlations with T2 behaviour, partially contributing to severity's lower predictive value as compared to the other constructs. Fourth, we assessed risk perceptions to explain other-directed behaviours (applying sunscreen on one's children) and not self-directed behaviour (applying sunscreen yourself). To which extent this aspect may have influenced our outcomes remains an issue for further research. HBM and PMT have been used for other-directed behaviours for assessing risk perceptions in parents concerning the protection of their children concerning other topics than skin cancer. Glik, Kronenfeld, and Jackson (1991) describe the application of the HBM for understanding predictors of risk perceptions of childhood injury among parents of preschoolers. Flynn, Lyman, and Prentice-Dunn (1995) used PMT to understand parent's protective actions of children with muscular dystrophy. Norman, Searle, Harrad, and Vedhara (2003) used PMT to study adherence behaviour of 151 parents with children with amblyopic. Yet, more research is needed to assess whether our outcomes can be replicated in studies addressing personal risk assessments. Fifth, assessments susceptibility may also reflect action outcome expectancies, as they include perceptions concerning various consequences of behaviour. Susceptibility estimations can be subject to different short- and long-term outcome expectancies. For instance, we did not include short-term risks such as burns. Hence, more research is also needed to further outline the role of different outcomes in risk perception research as well as the specific construct validity of susceptibility as a construct separate from outcome expectations (see also Brewer, Weinstein, Cuite, \& Herrington, 2004). Related to this are findings suggesting that measurements of severity and susceptibility can be improved when made more conditional to the action involved (Janssen, van Osch, de Vries, \& Lechner 2010; Ronis \& Harel, 1989). Whereas our studies assessed perceived susceptibility conditionally, it assessed severity in a more generic way.

In sum, our research findings suggest to use an additive function to assess risk perceptions and to regard risk perceptions as a distal factor that may influence (the impact of) other health-related cognitions such as attitudes, self-efficacy and intentions on health behaviour. Risk perceptions thus have the potential to trigger a cognitive process that may culminate in changing other cognitions and, finally, behaviour.

\section{References}

Abraham, C., \& Sheeran, P. (2005). The health belief model. In M. Conner \& P. Norman (Eds.), Predicting health behaviour (pp. 28-80). Berkshire: Open University Press.

Bandura, A. (1986). Social foundations of thought and action: A social cognitive theory. New York, NY: Prentice Hall.

Bandura, A. (1997). Self-efficacy: The exercise of control. New York, NY: Freeman.

Brewer, N.T., Chapman, G.B., Gibbons, F.X., Gerrard, M., McCaul, K.D., \& Weinstein, N.D. (2007). Meta-analysis of the relationship between risk perception and health behavior: The example of vaccination. Health Psychology, 26, 136-145.

Brewer, N.T., Weinstein, N.D., Cuite, C.L., \& Herrington, J.E. (2004). Risk perceptions and their relation to risk behavior. Annals of Behavioral Medicine, 27, 125-130.

Cameron, L. (2007). Illness risk representations and motivations to engage in protective behavior: The case of skin cancer risk. Psychology \& Health, 23, 91-112. 
Conner, M., Kirk, S., Cade, J., \& Barret, J. (2001). Why do women use dietary supplements? The use of the theory of planned behaviour to explore beliefs about their use. Social Science and Medicine, 52, 621-633.

Conner, M., \& Norman, P. (1994). Comparing the health belief model and the theory of planned behavior in health screening. In D.R. Rutter \& L. Quiine (Eds.), Social Psychology and Health: European Perspectives (pp. 1-24). Brookfield, VT: Avebury/ Ashgate.

Craciun, C., Schüz, N., Lippke, S., \& Schwarzer, R. (2010). Risk perception moderates how intentions are translated into sunscreen use. Journal of Behavioral Medicine, 33, 392-398.

de Vries, H., Kremers, S., Smeets, T., Brug, J., \& Eijmael, K. (2008). The effectiveness of tailored feedback and action plans in an intervention addressing multiple health behaviors. American Journal of Health Promotion, 22, 417-425.

de Vries, H., Lezwijn, J., Hol, M., \& van der Steeg, M. (2005). Skin cancer prevention: Behaviour and motives of Dutch adolescents. European Journal of Cancer Prevention, 14, 1439-1450.

de Vries, H., Mesters, I., van der Steeg, H., \& Honing, C. (2005). The general public's information needs and perceptions regarding hereditary cancer: An application of the integrated change model. Patient Education and Counseling, 56, 154-160.

de Vries, H., Mesters, I., van 't Riet, J., Willems, K., \& Reubsaet, A. (2006). Motives of Belgian adolescents for using sunscreen: The role of action plans. Cancer Epidemiology Biomarkers \& Prevention, 15, 1360-1366.

de Vries, E., van der Rhee, H.J., \& Coebergh, J.W. (2006). Trends, oorzaken, aanpak en gevolgen van de huidkankerepidemie in Nederland en Europa [Trends, causes, approach and consequences related to the skin-cancer epidemic in the Netherlands and Europe]. Nederlands Tijdschrift voor Geneeskunde, 150, 1108-1115.

Evans, M.G. (1991). The problem of analyzing multiplicative composites. American Psychologist, 46, 6-15.

Ferguson, G.A. (1976). Statistical analysis in psychology and education. Tokyo: McGraw-Hill.

Fishbein, M., \& Ajzen, I. (2010). Predicting and changing behavior: The reasoned action approach. New York, NY: Psychology Press.

Fitzpatrick, T.B. (1975). Soleil et peau. Journal of Medical Esthetics, 2, 33-34.

Floyd, D., Prentice-Dunn, S., \& Rogers, R.W. (2000). A meta-analysis of research on protection motivation theory. Journal of Applied Social Psychology, 30, 407-429.

Flynn, M.F., Lymann, R.D., \& Prentice-Dunn, S. (1995). Protection motivation theory and adherence to medical treatment regimens for muscular dystrophy. Journal of Social and Clinical Psychology, 14, 61-75.

Gagné, C., \& Godin, G. (2000). The theory of planned behavior: Some measurement issues concerning belief-based variables. Journal of Applied Social Psychology, 30, 2173-2193.

Glik, D., Kronenfeld, J., \& Jackson, K. (1991). Predictors of risk perceptions of childhood injury among parents of preschoolers. Health Education and Behavior, 18, 285-301.

Harrison, J.A., Mullen, P.D., \& Green, L.W. (1992). A meta-analysis of studies of the health belief model with adults. Health Education Research, 7, 107-116.

Hu, L.T., \& Bentler, P.M. (1999). Cutoff criteria for fit indices in covariance structure analysis: Conventional criteria versus new alternatives. Structural Equation Modeling, 6, $1-55$.

Janssen, E., van Osch, L., de Vries, H., \& Lechner, L. (2010). Measuring risk perceptions of skin cancer: Reliability and validity of different operationalizations. British Journal of Health Psychology, 16, 92-112.

Janz, N., \& Becker, M.H. (1984). The health belief model: A decade later. Health Education Quarterly, 11(1), 1-47.

Jones, F., Abraham, C., Harris, P., Schulz, J., \& Chrispin, C. (2001). From knowledge to action regulation: Modeling the cognitive prerequisites of sun screen use in Australian and UK samples. Psychology and Health, 16, 191-206. 
Lescano, C.M., \& Rodrigue, J.R. (1997). Skin cancer prevention behaviors among parents of young children. Children's Health Care, 26, 107-114.

Li, V.C., Coates, T.J., Spielberg, L.A., Ewart, C.K., Dorfman, S., \& Huster, J.W. (1984). Smoking cessation with young women in public family planning clinics: The impact of physician messages and waiting room media. Preventive Medicine, 13, 477-489.

Lippke, S., Ziegelmann, J.P., \& Schwarzer, S. (2004). Behavioral intentions and action plans promote physical exercise: A longitudinal study with orthopedic rehabilitation patients. Journal of Sport \& Exercise Psychology, 26, 470-483.

Maddux, J.E., \& Rogers, R.W. (1983). Protection motivation and self-efficacy: A revised theory of fear appeals and attitude change. Journal of Experimental Social Psychology, 19, 469-479.

Milne, S., Sheeran, P., \& Orbell, S. (2000). Prediction and intervention in health-related behavior: A meta-analytic review of protection motivation theory. Journal of Applied Social Psychology, 30, 106-143.

Muthén, L.K., \& Muthén, B.O. (2006). Mplus user's guide (4th ed.). Los Angeles, CA: Muthén \& Muthén.

Norman, P., \& Brain, K. (2007). Does dispositional optimism predict psychological responses to counseling for familial breast cancer? Journal of Psychosomatic Research, 63, 247-254.

Norman, P., \& Conner, M. (2005). Predicting and changing health behavior; future directions. In M. Conner \& P. Norman (Eds.), Predicting health behavior (pp. 1-27). Maidenhead: Open University Press.

Norman, P., Searle, A., Harrad, R., \& Vedhara, K. (2003). Predicting adherence to eye patching in children with amblyopia: An application of protection motivation theory. British Journal of Health Psychology, 8, 67-82.

O'Riordan, D.L., Lunde, K.B., Steffen, A.D., Maddock, J.E., Turrisi, R., Stapleton, J., Mallett, K., \& Hillhouse, J. (2006). Validity of beachgoers' self-report of their sun habits. Archives of Dermatology, 142, 1304-1311.

Prochaska, J.O., \& Velicer, W.F. (1997). The transtheoretical model of health behavior change. American Journal of Health Promotion, 12, 38-48.

Rimal, R.N., \& Real, K. (2003). Perceived risk and efficacy beliefs as motivators of change: Use of the risk perception attitude (RPA) framework to understand health behaviors. Human Communication Research, 29, 370-399.

Rogers, R.W. (1975). A protection motivation theory of fear appeals and attitude change. The Journal of Psychology, 91, 93-114.

Ronis, D.L., \& Harel, Y. (1989). Health beliefs and breast examination behaviors: Analyses of linear structural relations. Psychology \& Health, 3, 259-285.

Ruiter, R.A., Verplanken, B., Kok, G., \& Werrij, M.Q. (2003). The role of coping appraisal in reactions to fear appeals: Do we need threat information? Journal of Health Psychology, 8 , 465-474.

Schwarzer, R. (2008). Modeling health behavior change: How to predict and modify the adoption and maintenance of health behaviors. Applied Psychology, 57(1), 1-29.

Schwarzer, R., Schulz, B., Ziegelmann, J.P., \& Lippke, S. (2007). Adoption and maintenance of four health behaviors: Theory-guided longitudinal studies on dental flossing, seat belt use, dietary behavior, and physical activity. Annals of Behavioral Medicine, 33, 156-166.

Severi, G., Cattaruzza, M.S., Baglietto, L., Boniol., M., Dore, J.F., Grivegnee, A.R.,... Autier, P. (2002). Sun exposure and sun protection in young European children: An EORTC multicentric study. European Journal of Cancer, 38, 820-826.

Slovic, P. (1987). Perception of risk. Science, 236, 280-285.

Sniehotta, F.F., Scholz, U., \& Schwarzer, R. (2006). Action plans and coping plans for physical exercise: A longitudinal intervention study in cardiac rehabilitation. British Journal of Social Psychology, 11, 23-37. 
Sutton, S. (1987). Social-psychological approaches to understanding addictive behaviours: Attitude-behaviour and decision-making models. British Journal of Addiction, 82, 355-370.

Turner, L.R., \& Mermelstein, R.J. (2005). Psychosocial characteristics associated with sun protection practices among parents of young children. Journal of Behavioral Medicine, 28, $77-90$.

Ulleberg, P., \& Rundmo, T. (2003). Personality, attitudes and risk perception as predictors of risky driving behaviour among young drivers. Safety Science, 41, 427-443.

van der Geer, S., Reijers, H.A., van Tuijl, H.F., de Vries, H., \& Krekels, G.A. (2010). Need for a new skin cancer management strategy. Archives of Dermatology, 146, 332-336.

van Osch, L., Reubsaet, A., Lechner, L., \& de Vries, H. (2008). The formation of specific action plans can enhance sun protection behavior in motivated parents. Preventive medicine, 47, 127-132.

Weinstein, N.D. (1988). The precaution adoption process. Health Psychology, 7, 355-386.

Weinstein, N.D., \& Kwitel, A. (2007). Risk perceptions: Assessment and relationship to influenza vaccination. Health Psychology, 26, 146-151.

Weinstein, N.D., \& Nicolich, M. (1993). Correct and incorrect interpretations of correlations between risk perceptions and risk behaviors. Health Psychology, 12, 235-245.

Whiteman, D.C., Whiteman, C.A., \& Green, A.C. (2001). Childhood sun exposure as a risk factor for melanoma: A systematic review of epidemiologic studies. Cancer Causes and Control, 12, 69-82. 